\title{
Controlling the Energy Absorption Capability of a Unidirectional Carbon Fiber Reinforced Plastic Tube Using a Double-Sided Plug
}

\author{
Masahito Ueda, Takehito Tsuji, Tae-Kun Jeong \\ Department of Mechanical Engineering, College of Science and Technology, Nihon University, Tokyo, Japan \\ Email: ueda@mech.cst.nihon-u.ac.jp
}

Received 12 October 2014; revised 8 November 2014; accepted 28 November 2014

Copyright (C) 2015 by authors and Scientific Research Publishing Inc.

This work is licensed under the Creative Commons Attribution International License (CC BY). http://creativecommons.org/licenses/by/4.0/

\section{c) (i) Open Access}

\begin{abstract}
Quasi-static and dynamic crush tests of a unidirectional carbon fiber reinforced plastic (CFRP) circular tube were performed, and its energy absorption capability was controlled using a doublesided plug. It was revealed in the quasi-static crush test that its energy absorption capability was controlled significantly from 8 to $178 \mathrm{~kJ} / \mathrm{kg}$ by changing the curvature of the plug. The range of energy absorption covers almost all types of CFRP tube reported in the literature. A dynamic crush test up to $55 \mathrm{~km} / \mathrm{h}$ was then performed by drop weight impact tests. The energy absorption capability of the CFRP tube in the dynamic crush test was very similar to that in the quasi-static crush test. A simple design concept of energy absorption for a CFRP tube, using the double-sided plug, was proposed.
\end{abstract}

\section{Keywords}

Polymer Matrix Composite, Carbon Fiber, Progressive Crushing, Energy Absorption, Crush Can

\section{Introduction}

The energy absorption capability of a well-designed carbon fiber reinforced plastic (CFRP) laminate is higher than that of metallic materials [1]. CFRP laminates are, therefore, being used as crash energy absorbing structures [2]-[10].

CFRP absorbs crush energy by brittle fracture while metallic materials absorb by plastic buckling. These failure modes are called progressive crushing and progressive folding, respectively. Because the energy absorbing 
mechanisms in progressive crushing and progressive folding are completely different, the design methodology of a CFRP crash energy absorbing structure is different from that of metallic materials.

The energy absorption capability is strongly dependent on the stacking sequence [1] [11]-[13]. Even when the same stacking sequence is adopted, the energy absorption capability changes depending on the cross-sectional features [1] [14]-[16]. The fracture behavior and resultant energy absorption capability of a CFRP laminate is strongly affected by a combination of the stacking sequence and the cross-sectional features. The mutual interaction and resultant crushing behavior can be predicted by numerical simulation [17]-[21], although countless simulations are required for an optimized design.

Various plugs have been proposed for axial crushing of a CFRP tube to enhance energy absorption capability [22]-[28]. An outward-splaying and an inward-folding plug have been investigated, by which the energy absorption capability of a CFRP tube was increased by enforcing severe damage to the CFRP. The results implied that the energy absorption capability of a single CFRP tube could be adjusted to meet each design target if the damage extent was controlled by a plug [29].

In this study, a double-sided plug was proposed to control the energy absorption capability of a single CFRP tube. The plug was composed of an inner and an outer plug which constrained the inner- and outer-sides of the wall of a CFRP tube. The energy absorption of the CFRP tube was controlled by changing the plug. Quasi-static and dynamic crush tests were performed to investigate the suitability of the plug, from which a simple design concept for energy absorption of a CFRP tube was proposed.

\section{Experiment Methodology}

\subsection{Material and Specimen Configuration}

A CFRP tube with a circular cross-section was fabricated from a prepreg sheet (PYROFIL TR30S/\#380, Mitsubishi Rayon). The prepreg sheet was wound onto an aluminum mandrel of $50 \mathrm{~mm}$ inner diameter, and bagged by a heat resistive film. The prepreg sheet was then cured at $130^{\circ} \mathrm{C}$ for 90 min under a vacuum condition. The stacking sequence was unidirectional, and a total of twelve prepreg sheet were stacked. The fiber volume fraction was about $60 \%$. The aluminum mandrel was removed after consolidation of the CFRP tube. The consolidated CFRP tube was cut into $80 \mathrm{~mm}$ lengths with tube walls approximately $2.9 \mathrm{~mm}$ thick. No chamfer was machined on the specimen because progressive crushing of the CFRP tube started at the tip as a result of the curvature on the inner-plug.

The unusual unidirectional stacking sequence was adopted in this study because the plug was designed to control energy absorption by controlling the amount of fiber fracture in $0^{\circ}$-ply. Other stacking sequences of a CFRP tube can also be used. The significance of the $0^{\circ}$-ply on the energy absorption of a CFRP tube in axial crushing is shown by means of the plug excluding the effect of the stacking sequence [30].

\subsection{Double-Sided Plug}

A one-sided plug such as an outward-splaying or an inward-folding plug was used to increase the energy absorption of a CFRP tube [22]-[28]. The plugs constrained the inside or outside surface of the wall of the CFRP tube by which the fractured CFRP was ejected outward or inward from the tube. It was shown that an inward-folding plug yielded higher specific energy absorption. The results implied that the energy absorption of a single CFRP tube could be controlled if the extent of the damage was controlled by a special plug, which contributed to the simple design of a crush energy absorbing structure.

In this study, a double-sided plug was introduced to control the energy absorption capability of a CFRP tube. The double-sided plug constrains both the inside and outside surfaces of the wall of a CFRP tube in the axial crushing. In the case of a one-sided plug, the CFRP tube tends to swell to the other side in the crushing because the wall of the CFRP tube is supported from one side by the plug, which would cause undesirable blooming failure of the tube. A double-sided plug prevents the blooming failure, and controls the extent of the fracture. The plug is also effective in moderating the initial peak load by enforcing continuous fracture of a CFRP tube up to the stable crushing region and reducing the fluctuations of a sustained crushing load. These are the requirements for crash safety in preventing injury of the passengers.

The double-sided plug for a CFRP circular tube is shown in Figure 1. The double-sided plug is composed of an inner and an outer plug, which support the inside and outside surfaces of the wall of a CFRP tube in the 
crushing. A CFRP tube is inserted into the plug at the top of the plug in the figure. The inner and outer plugs have respective curvature radii which are denoted by $R_{i}$ and $R_{o}$. These plugs are connected by bolts and nuts with a spacing of $3 \mathrm{~mm}$ using shims, which is approximately the thickness of the CFRP tube used in this study. The shim has a knife-edged shape, which enables ejection of fractured CFRP from the plug. The double-sided plug is a type of outward-splaying plug. The plug and shims are made of S45C (Japanese Industrial Standard) steel.

The double-sided plug guides the wall of a CFRP tube under axial crushing by constraining both the inside and the outside surfaces. The amount of fiber fracture in $0^{\circ}$-ply of a CFRP tube is controlled by changing the radius of curvature of the plugs. The pairs of curvature radii of the double-sided plugs used in this study are shown in Table 1. A total of 8 sets of plugs were prepared and supplied for the crushing tests. Note that the clearance $c$ is constant for the No. 3 to No. 8 plugs and not constant for the No. 1 and No. 2 plugs.

\subsection{Specific Energy Absorption}

Specific energy absorption $\left(E_{s}\right)$ was used to compare energy absorption efficiencies. Specific energy absorption is defined as:

$$
E_{s}=\frac{1}{M} \int_{0}^{L_{e}} P \mathrm{~d} L=\frac{P_{a} L_{e}}{M} \quad[\mathrm{~kJ} / \mathrm{kg}],
$$

where $P$ is the progressive crushing load, $L_{e}$ is the crushed length of the specimen, $M$ is the mass of the specimen, and $P_{a}$ is the average progressive crushing load. Here, the initial transition region from 0 to $10 \mathrm{~mm}$ crushing length was eliminated to calculate the specific energy absorption, and specimen length was substituted in $L_{e}$. This condition results in a somewhat higher calculated specific energy absorption than the actual value when the

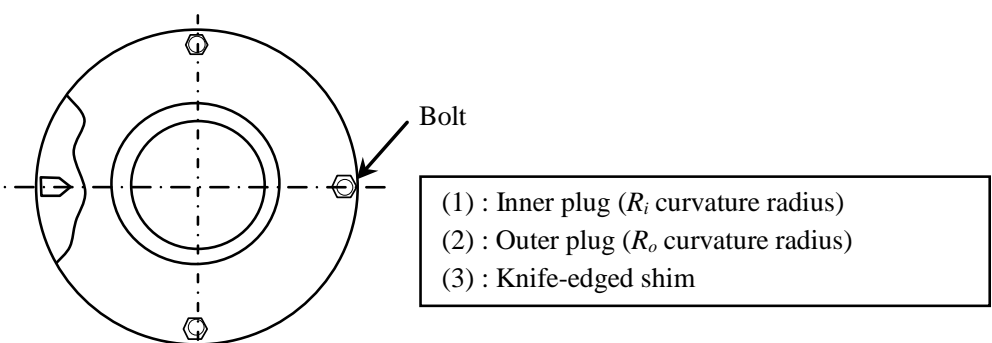

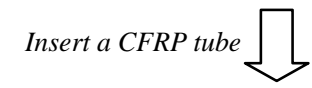

(2)

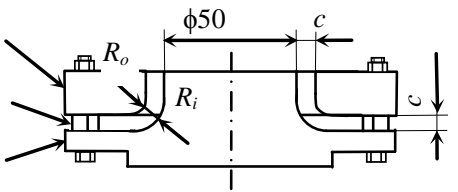

$c$ : Clearance between the plug ( $c \approx$ Thickness of CFRP tube )

Figure 1. Assembly drawing of the double-sided plug for a CFRP circular tube.

Table 1. Pairs of curvature radius for the double-sided plug and resultant specific energy absorption from quasi-static crush tests.

\begin{tabular}{ccccccccc}
\hline Plug No. & 1 & 2 & 3 & 4 & 5 & 6 & 7 & 8 \\
\hline$R_{o}[\mathrm{~mm}]$ & 0 & 0 & 0 & 1 & 2 & 3 & 4 & 5 \\
$R_{i}[\mathrm{~mm}]$ & 1 & 2 & 3 & 4 & 5 & 6 & 7 & 8 \\
Clearance $c$ & Not constant & & \multicolumn{7}{c}{ Constant } \\
Specific energy absorption ${ }^{*}[\mathrm{~kJ} / \mathrm{kg}]$ & $168(163)$ & $178(164)$ & $108(96)$ & $36(34)$ & $15(17)$ & $18(18)$ & $9(11)$ & $8(10)$
\end{tabular}

*Mean value. The specific energy absorption was calculated with the elimination of the initial transition region. The specific energy absorption in round bracket included the initial transition region. 
crushing length (specimen length) is limited. The difference in the energy absorption reduces with the increase in crushing length. The condition is used in this study to show the direct relationship between the curvature radius of the plug and specific energy absorption excluding the effect of crushing length. In particular, crushing length is changed by impact speed in dynamic crush test, which affects actual specific energy absorption. The specific energy absorption was also calculated including the initial transition region, and shown for reference. The weight of the plug was not considered when calculating the specific energy absorption, because the practical design of the plug was beyond the scope of this study.

\subsection{Quasi-Static Crush Test}

Quasi-static crush tests were performed between parallel steel platens of a universal testing machine (AG-IS 150 $\mathrm{KN}$, Shimadzu). A compressive load was applied to a specimen quasi-statically under displacement control with a crosshead speed of $1.0 \mathrm{~mm} / \mathrm{min}$. The test was performed until $40 \mathrm{~mm}$ of crushing length. The data on the applied load and the shortening of the platens were collected using a digital data acquisition system.

\subsection{Dynamic Crush Test}

Dynamic crush tests were performed using a drop weight impact test to investigate the effect of impact speed on the energy absorption capability. The impactor was dropped from a maximum height of $11.9 \mathrm{~m}$, with a maximum speed just before impact on a specimen of about $55 \mathrm{~km} / \mathrm{h}$. The impact speed was controlled by adjusting the height. The crushing length of the CFRP tube depends on the impact speed.

The test fixture is shown in Figure 2. The impactor had a flat impact face as shown in Figure 2(a). The impactor weighed $65 \mathrm{~kg}$. The impact load was measured using a load cell (CLP-500KNB, Tokyo Sokki Kenkyujo). The CFRP tube installed in the double-sided plug was placed on the load cell using a positioning jig, and the impactor directly hit the CFRP tube in the test. The motion of the impactor was recorded using a high speed camera (Phantom V7.1, Vision Research). The crushed length of the CFRP tube was measured from the image of the high speed camera using image analysis software (PcVector, OKK Inc.), and it was synchronized with the date from load cell to obtain load-crush length curve.

\section{Results and Discussion}

\subsection{Quasi-Static Crush Test}

\subsubsection{Load-Crush Length Curve}

Figure 3 shows a typical example of load-crush length curves obtained from quasi-static crush tests of the unidirectional CFRP tube installed in the double-sided plug. The curvature set used for the plug are indicated in the figure. For example, if the outer curvature radius is $R_{o}=2 \mathrm{~mm}$ and inner curvature radius is $R_{i}=5 \mathrm{~mm}$, it is indicated as $(2,5)$.

The load increased with increasing length of crushing. Local failure (delamination) was initiated at the tip of the CFRP tube, shown by a slight drop in the load. The load again increased up to the sustained crushing load when the double-sided plug had a small radius of curvature, and a clear initial peak load was not observed. However, the load did not increase again when the double-sided plug had a large radius of curvature.

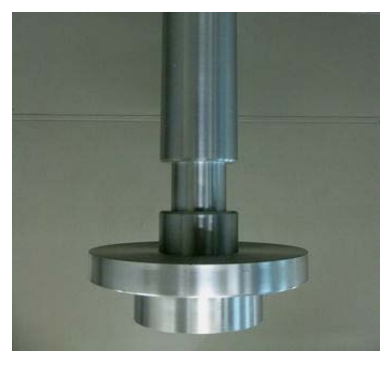

(a)

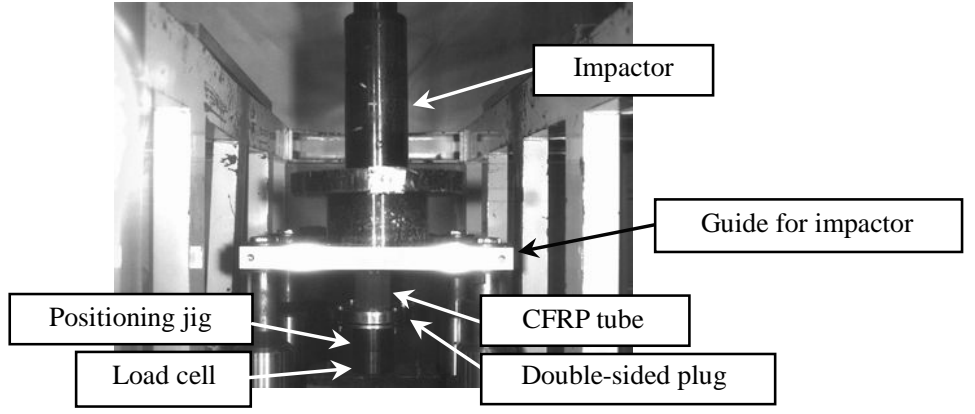

(b)

Figure 2. Test fixtures for the dynamic crush test. (a) Impactor; (b) High speed camera image at impact. 
In the case of the double-sided plug of $\left(R_{o}, R_{i}\right)=(0,1)$, and $(0,2)$, fluctuations of the sustained crushing load were observed. Increasing the clearance $c$ developed a discontinuous fracture in the crushing, which resulted in fluctuations of the sustained crushing load. However, it was not observed for other constant-clearance plugs because of the regulated fracture of the CFRP tube.

\subsubsection{Controlling Energy Absorption}

The sustained crushing load was higher when the radius of curvature of the plug was smaller. Figure 4 shows a comparison of the specific energy absorption versus the radius of curvature of the plugs. The specific energy absorption was also summarized in Table 1. The tests were performed three times for each testing conditions, and the results shown are the averaged values.

Smaller curvature radii showed higher specific energy absorption. The maximum specific energy absorption was $178 \mathrm{~kJ} / \mathrm{kg}$ when a double-sided plug of $\left(R_{o}, R_{i}\right)=(0,2)$ was used. By contrast, the minimum specific energy absorption was $8 \mathrm{~kJ} / \mathrm{kg}$ when a double-sided plug of $\left(R_{o}, R_{i}\right)=(5,8)$ was used. The difference in the specific energy absorption was $170 \mathrm{~kJ} / \mathrm{kg}$, in which the range of energy absorption was controlled by changing the radius of curvature of the plug. The plug used and the resultant energy absorption of the CFRP tube corresponded on a one-to-one basis, except for the plug of $\left(R_{o}, R_{i}\right)=(0,1)$. The double-sided plug can be selected using Figure 4 when the required energy absorption has been previously determined.

\subsubsection{Fracture Behavior}

Figure 5 shows the CFRP tubes after the tests. The plug was removed after the tests and only the CFRP tubes are shown in the figure, and the photographs were taken placing the fractured CFRP tube upside down. Delamination

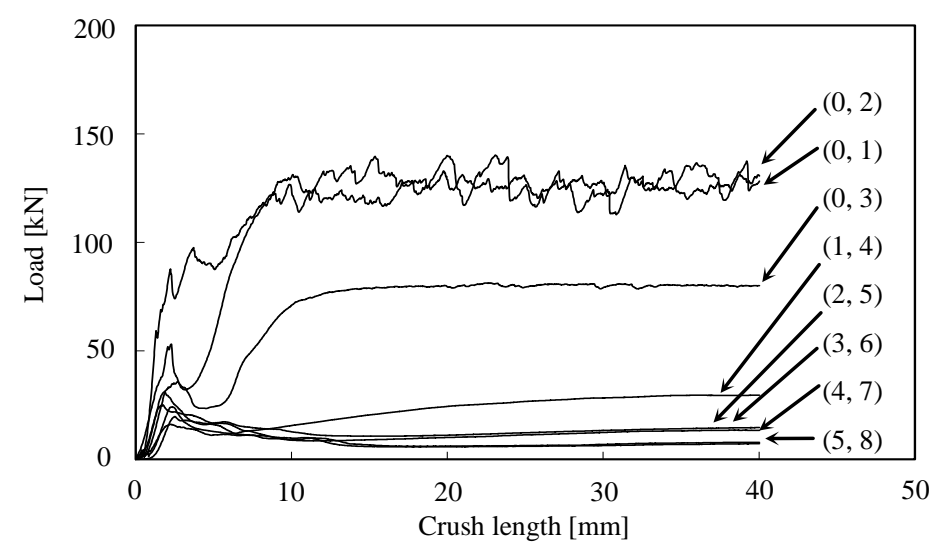

Figure 3. Load-crush length curves from the quasi-static crush tests of a unidirectional CFRP tube installed with a double-sided plug.

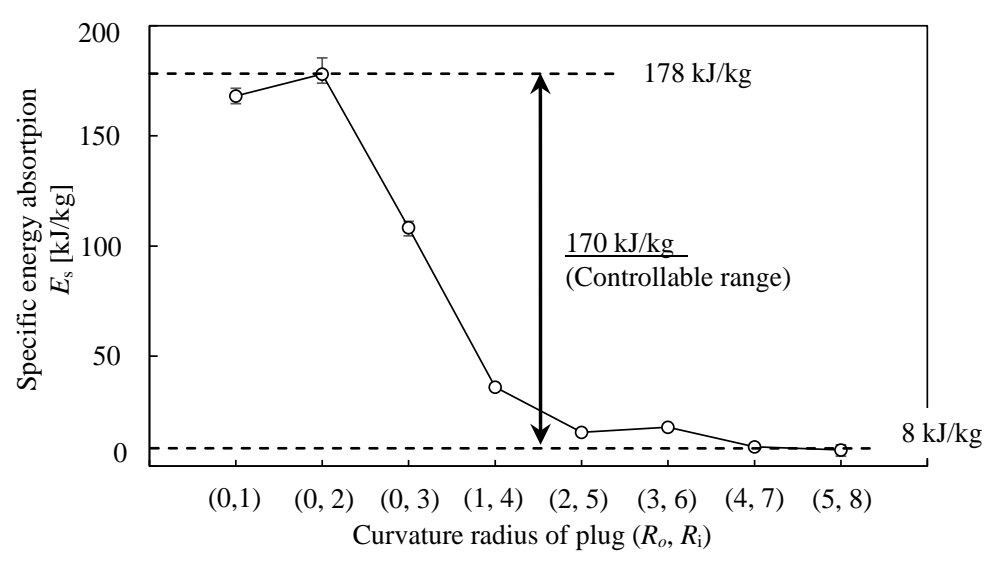

Figure 4. Specific energy absorption from the quasi-static crush tests of a unidirectional CFRP tube installed with a double-sided plug. 
and splitting failure were observed for every specimen. In the case of the double-sided plug of $\left(R_{o}, R_{i}\right)=(0,2)$, the CFRP tube remained deformed. By contrast, in the case of the double-sided plug of $\left(R_{o}, R_{i}\right)=(5,8)$, the CFRP sprang back almost to the original shape when the plug was removed. The spring back was small when the radius of curvature of the plug was small.

Then, the specimens were filled with epoxy resin (105/206, West system) to observe the crash zone. After the resin was completely cured, the specimen was cut along the loading direction. The polished section of crash zone was observed using an optical microscope, and is shown in Figure 6.

In the case of the double-sided plug of $\left(R_{o}, R_{i}\right)=(0,2)$, some delaminated layers were missing due to the severe damage, which was noticeable around outer curvature constrainer due to smaller radius of outer curvature. Starting point of fiber fracture due to bending was clearly observed. Therefore, the fracture mode of the CFRP tube was fiber fracture, delamination and splitting, which resulted in an $E_{s}=178 \mathrm{~kJ} / \mathrm{kg}$. In the case of the double-sided plug of $\left(R_{o}, R_{i}\right)=(5,8)$, delamination was observed but no fiber fracture. The fracture mode of the CFRP tube was, therefore, delamination and splitting, which resulted in an $E_{s}=8 \mathrm{~kJ} / \mathrm{kg}$. The energy absorption capability of the CFRP tube was controlled significantly by changing the amount of fiber fracture.

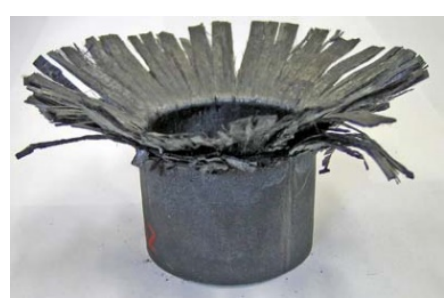

$E_{\mathrm{s}}=178 \mathrm{~kJ} / \mathrm{kg}$

(1) $\left(R_{0}, R_{\mathrm{i}}\right)=(0,2)$

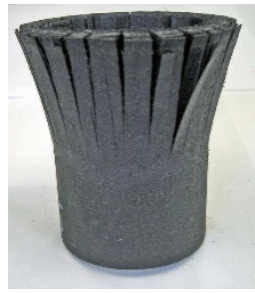

$E_{\mathrm{s}}=15 \mathrm{~kJ} / \mathrm{kg}$

(4) $\left(R_{\mathrm{o}}, R_{\mathrm{i}}\right)=(2,5)$

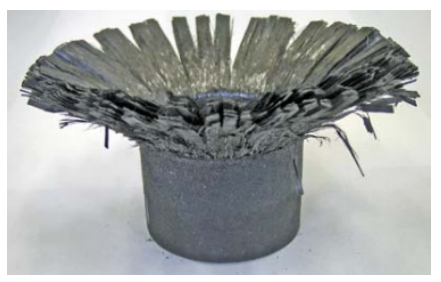

$E_{\mathrm{s}}=108 \mathrm{~kJ} / \mathrm{kg}$

(2) $\left(R_{0}, R_{\mathrm{i}}\right)=(0,3)$

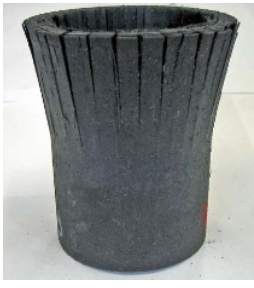

$E_{\mathrm{s}}=18 \mathrm{~kJ} / \mathrm{kg}$

(5) $\left(R_{\mathrm{o}}, R_{\mathrm{i}}\right)=(3,6)$

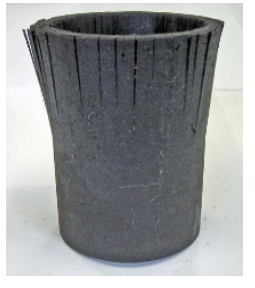

$E_{\mathrm{s}}=9 \mathrm{~kJ} / \mathrm{kg}$

$\left(R_{0}, R_{\mathrm{i}}\right)=(4,7)$

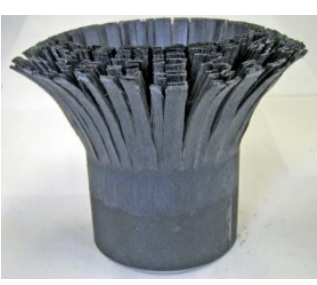

$E_{\mathrm{s}}=36 \mathrm{~kJ} / \mathrm{kg}$

(3) $\left(R_{0}, R_{\mathrm{i}}\right)=(1,4)$

Figure 5. Unidirectional CFRP tubes after quasi-static crushing tests; the double-sided plug was removed after the test to take the photographs.

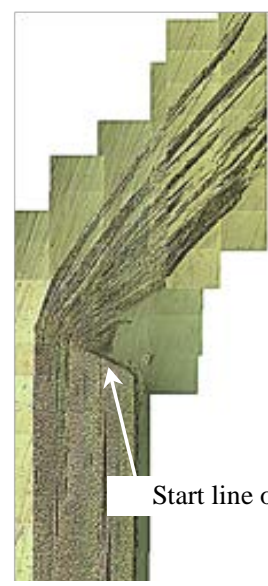

(a)

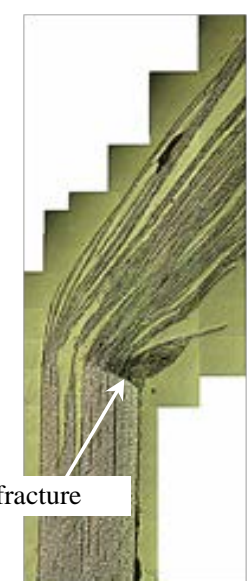

(b)

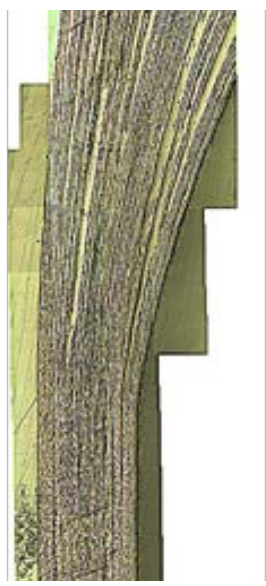

(c)

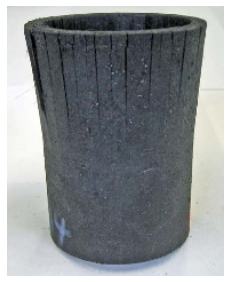

$E_{\mathrm{s}}=8 \mathrm{~kJ} / \mathrm{kg}$

(7) $\left(R_{0}, R_{\mathrm{i}}\right)=(5,8)$

Figure 6. Polished sections of crash zone. (a) $\left(R_{o}, R_{i}\right)=(0,2)$; (b) $\left(R_{o}, R_{i}\right)=(0,3)$; (c) $\left(R_{o}, R_{i}\right)=(1,4)$; (d) $\left(R_{o}\right.$, $\left.R_{i}\right)=(5,8)$. 
The maximum specific energy absorption was obtained when the double-sided plug of $\left(R_{o}, R_{i}\right)=(0,2)$ was used. Figure 7(a) and Figure 7(b) show sectional images of the crushing of the CFRP tube in the plug when the double-sided plug of $\left(R_{o}, R_{i}\right)=(0,3)$ was used. An opening around the outer radius of curvature $R_{o}$ was observed because the wall of the CFRP tube could not follow the outer curvature exactly because of the stiffness. Because the wall of the CFRP tube was pressed to deform along the inner curvature of the plug, the fiber fracture around the inner radius of curvature $R_{i}$ increased when the double-sided plug of $\left(R_{o}, R_{i}\right)=(0,2)$ was used (Figure 7(c)), which increased the energy absorption. However, the larger clearance for the plug of $\left(R_{o}, R_{i}\right)=(0,1)$ caused larger fluctuations of the sustained crushing load, which resulted in degradation of the energy absorption.

Specific energy absorptions of $178 \mathrm{~kJ} / \mathrm{kg}$ and $8 \mathrm{~kJ} / \mathrm{kg}$ are one of the highest and lowest values among the various types of CFRP reported in the literature [1]. The amount of splitting and delamination were almost the same independent of the radius of curvature, and the energy absorption was exclusively done through fiber fracture. Fiber fracture in $0^{\circ}$-ply plays a significant role in energy absorption in the axial crushing.

\subsection{Dynamic Crush Test}

\subsubsection{The Effect of Crushing Speed on Load-Crush Length Curve}

Dynamic crush tests were performed to investigate the impact speed on the energy absorption capability of the CFRP tube installed with a double-sided plug. Here, the effect of the crushing speed was studied using the double-sided plug of $\left(R_{o}, R_{i}\right)=(0,2)$ which demonstrated the maximum energy absorption. Dynamic crush tests were performed with different impactor speeds of 20, 25, 30, 35, 40, 45 and $55 \mathrm{~km} / \mathrm{h}$. Figure 8 shows the load-crush length curves obtained in the dynamic crush tests. The results obtained in the quasi-static crush tests (loading speed was $1.0 \mathrm{~mm} / \mathrm{min}$ ) are also shown in the figure. Because the impactor hit the guide shown in Figure 2 as a result of the short specimen length when the crush length exceeded $60 \mathrm{~mm}$, the results were shown until a crush length of $60 \mathrm{~mm}$ was reached. The impactor only hit the guide when the impact speed was $55 \mathrm{~km} / \mathrm{h}$.

In the initial transition region, the load showed a modest increase compared with that in the quasi-static test. It was caused by the inertia of the positioning jig between the load cell and the CFRP tube. The load-crush length curves almost coincided independent of the crushing speed except for the initial transition region. Figure 9 shows a comparison of the average sustained crushing loads versus the impact speeds. The average sustained crushing loads were calculated with the elimination of the initial transition region to show the direct relationship between the radius of curvature of the plug and the specific energy absorption, as mentioned in Section 2.3. The average sustained crushing loads were almost constant and independent of the impact speed. The energy absorption capability of the CFRP tube installed with a double-sided plug did not change, irrespective of the impact speed.

Figure 10 shows the CFRP tubes after the dynamic crush test when the impact speed was $35 \mathrm{~km} / \mathrm{h}$. The fracture modes of the CFRP were fiber fracture, delamination and splitting, which were identical with those of the CFRP tube after the quasi-static crush tests. The average sustained crushing load was almost the same as that from the quasi-static crush tests. It was reported that the energy absorption capability of the CFRP changed with impact speed because of the transition of the fracture mode [15] [31]-[33]. However, the double-sided plug constrained the fracture mode of the CFRP tube, which resulted in almost the same energy absorption irrespective of the impact speed.

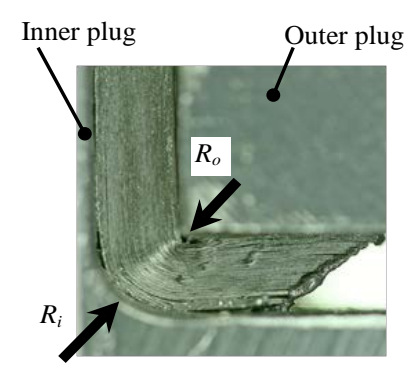

(a)

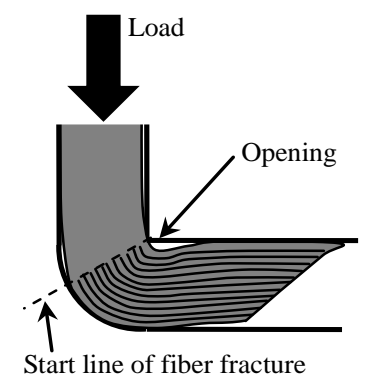

(b)

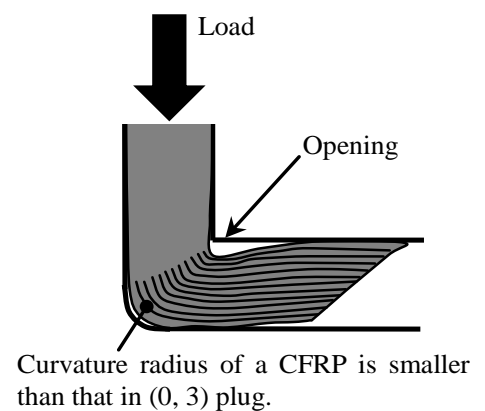

(c)

Figure 7. Crushing of a CFRP tube in the plug. (a) Cross sectional picture $\left(R_{o}, R_{i}\right)=(0,3)$; (b) Schematic of cross section $\left(R_{o}\right.$, $\left.R_{i}\right)=(0,3)$; (c) Schematic of cross section $\left(R_{o}, R_{i}\right)=(0,2)$. 


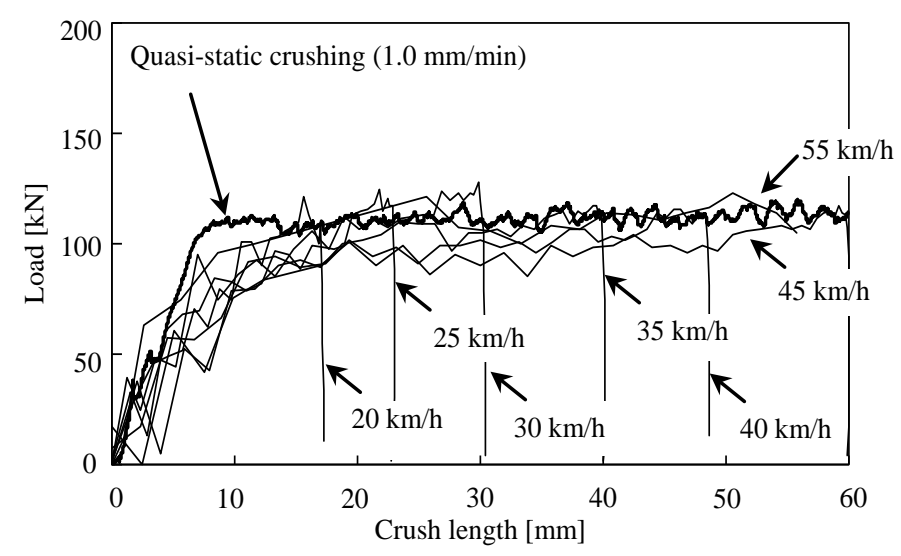

Figure 8. Load-crush length curves from the dynamic crush tests of a unidirectional CFRP tube installed with the double-sided plug of $\left(R_{o}\right.$, $\left.R_{i}\right)=(0,2)$.

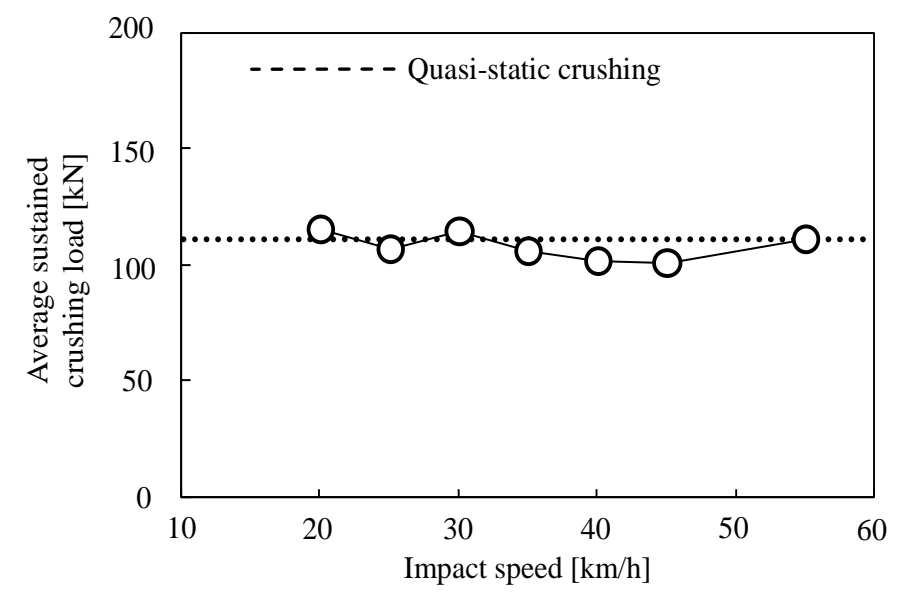

Figure 9. Comparison of average sustained crushing load versus impact speed.

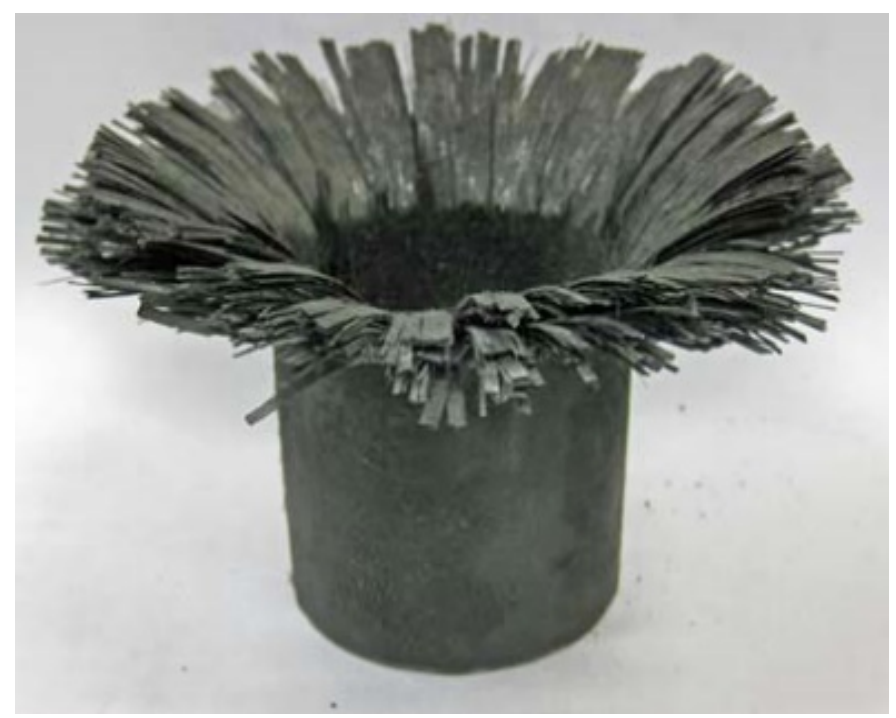

Figure 10. A unidirectional CFRP tube after a dynamic crush test of $35 \mathrm{~km} / \mathrm{h}$; The $\left(R_{o}, R_{i}\right)=(0,2)$ plug was removed after the test. 
Figure 11 shows the load-crush length curves for the dynamic crush test when the double-sided plug of $\left(R_{o}\right.$, $\left.R_{i}\right)=(5 \mathrm{~mm}, 8 \mathrm{~mm})$ was used. The impact speed was $55 \mathrm{~km} / \mathrm{h}$. The load-crush length curve was almost the same as that from the quasi-static crush test even when the double-sided plug had a large radius of curvature.

\subsubsection{The Effect of Crushing Speed on Specific Energy Absorption}

Figure 12 shows a comparison of the specific energy absorption of the unidirectional CFRP tube installed with the double-sided plugs for the quasi-static and dynamic crush tests. The impact speed of the dynamic crush test was kept constant at $55 \mathrm{~km} / \mathrm{h}$, and the curvature set for the plug was changed. The plug of $\left(R_{o}, R_{i}\right)=(0,1)$ was not used here because the energy absorption decreased as compared with the plug of $\left(R_{o}, R_{i}\right)=(0,2)$. The dynamic crush test results with the plug of $\left(R_{o}, R_{i}\right)=(3,6)$ are not shown in the figure because of errors in data collection.

The specific energy absorption increased with a decrease in the radius of curvature of the plug. Some difference was observed when a comparison was done at the same curvature radius of the plug. In the drop weight impact test, the impact load was applied eccentrically to the CFRP tube because the impactor slightly inclined when it released, which could affect the resultant energy absorption. However, the results almost coincided with those in quasi-static crush tests.

The fracture mode was the same independent of the impact speed when the same double-sided plug was used. Because the double-sided plug constrained the fracture mode of the CFRP tube, the energy absorption was independent of the impact speed when the plug was applied. Energy absorption of a CFRP tube can be designed

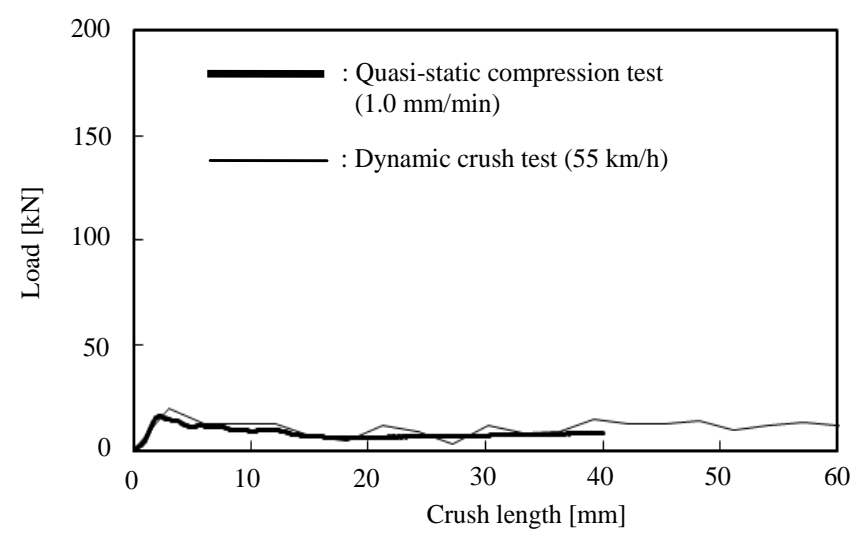

Figure 11. Load-crush length curves from a dynamic crush test of $55 \mathrm{~km} / \mathrm{h}$ of a unidirectional CFRP tube installed with the doublesided plug of $\left(R_{o}, R_{i}\right)=(5,8)$.

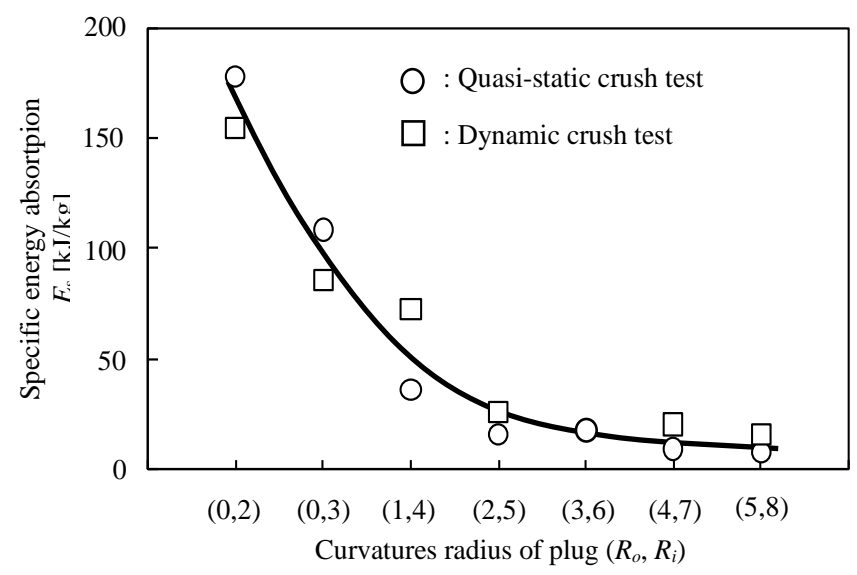

Figure 12. Comparison of specific energy absorptions from quasi-static and dynamic crush tests of a unidirectional CFRP tube installed with a double-sided plug. 
by selecting the appropriate double-sided plug using the results in the quasi-static crush tests when the required energy absorption has previously been determined.

\section{Conclusions}

A double-sided plug was used for progressive crushing of a CFRP tube to control its energy absorption capability. Quasi-static and dynamic crush tests of a unidirectional CFRP tube were performed to study the suitability of the plug. The results obtained in this study are summarized as follows.

1) The wide range capability of energy absorption of a unidirectional CFRP tube was demonstrated for changing curvature sets of the double-sided plug. The plug used and the resultant energy absorption of the CFRP tube corresponded on a one-to-one basis. Energy absorption of the CFRP tube can be designed by selecting a suitable plug.

2) The macroscopic fracture modes of the unidirectional CFRP tube were fiber fracture, delamination and splitting. Energy absorption of the unidirectional CFRP was mostly done by the fiber fracture, and the energy absorption capability was controlled by changing the amount of fiber fracture.

3) The range of specific energy absorption obtained in this study was from $8 \mathrm{~kJ} / \mathrm{kg}$ to $178 \mathrm{~kJ} / \mathrm{kg}$ which were among the lowest and highest values among the various types of CFRP reported in the literature. Fiber fracture in $0^{\circ}$-ply plays a significant role in energy absorption in the axial crushing of a CFRP tube.

4) The energy absorption capability of a CFRP tube with a double-sided plug was not dependent on the impact speed because the fracture mode did not change as a function of the impact speed. Energy absorption of a unidirectional CFRP tube can be designed by selecting the appropriate double-sided plug using the results from the quasi-static crush tests.

\section{References}

[1] Mamalis, A.G., Manolakos, D.E., Demosthenous, G.A. and Ioannidis, M.B. (1998) Crashworthiness of Composite Thin-Walled Structures. CRC Press, Boca Raton.

[2] Farley, G.L. (1987) Crash Energy Absorbing Subfloor Beam Structure. Journal of the American Helicopter Society, 32, 28-38. http://dx.doi.org/10.4050/JAHS.32.28

[3] Jackson, K.E. and Lyle, K.H. (2003) Full-Scale Crash Test and Finite Element Simulation of a Composite Prototype Helicopter. NASA/TP-2003-212641.

[4] Jacob, G.C., Fellers, J.F., Simunovic, S. and Starbuck, J.M. (2002) Energy Absorption in Polymer Composites for Automotive Crashworthiness. Journal of Composite Materials, 36, 813-850. http://dx.doi.org/10.1177/0021998302036007164

[5] Auto Technology (2003) Mercedes-Benz SLR McLaren: Technology for the 21st-Century. 28-31.

[6] Bisagni, C., Di Pietro, G., Fraschini, L. and Terletti, D. (2005) Progressive Crushing of Fibre-Reinforced Composite Structural Components of a Formula One Racing Car. Composite Structures, 68, 491-503. http://dx.doi.org/10.1016/j.compstruct.2004.04.015

[7] Aoki, Y., Kim, H-S. and Ben, G. (2009) Impact Strength and Response Behaviour of CFRP Guarder Belt for Side Collision of Automobiles. International Journal of Crashworthiness, 14, 469-476. http://dx.doi.org/10.1080/13588260902826513

[8] Kawamura, N. (2011) The Light Weight Body Structure Technologies of Lexus LFA. Proceeding of 12th Japan International SAMPE Symposium, Tokyo, 9-11 November 2011.

[9] Yang, Y., Wu, X. and Hamada, H. (2013) Application of Fibre-Reinforced Composites Beam as Energy Absorption Member in Vehicle. International Journal of Crashworthiness, 18, 103-109. http://dx.doi.org/10.1080/13588265.2012.756309

[10] Park, C.-K., Kan, C.-D. and Hollowell, W.T. (2014) Evaluation of Crashworthiness of a Carbon-Fibre-Reinforced Polymer (CFRP) Ladder Frame in a Body-on-Frame Vehicle. International Journal of Crashworthiness, 19, 27-41. http://dx.doi.org/10.1080/13588265.2013.830940

[11] Hull, D. (1991) A Unified Approach to Progressive Crushing of Fibre-Reinforced Composite Tubes. Composites Science and Technology, 40, 377-421. http://dx.doi.org/10.1016/0266-3538(91)90031-J

[12] Hamada, H., Ramakrishna, S. and Saito, H. (1996) Effect of Fiber Orientation on the Energy Absorption Capability of Carbon Fiber/PEEK Composite Tubes. Journal of Composite Materials, 30, 947-963. http://dx.doi.org/10.1177/002199839603000806 
[13] Ochelski, S. and Gotowicki, P. (2008) Experimental Assessment of Energy Absorption Capability of Carbon-Epoxy and Glass-Epoxy Composites. Composite Structures, 87, 215-224. http://dx.doi.org/10.1016/j.compstruct.2008.01.010

[14] Farley, G.L. (1986) Effect of Specimen Geometry on the Energy Absorption Capability of Composite Materials. Journal of Composite Materials, 20, 390-400. http://dx.doi.org/10.1177/002199838602000406

[15] Mamalis, A.G., Yuan, Y.B. and Viegelahn, G.L. (1992) Collapse of Thin-Wall Composite Sections Subjected to High Speed Axial Loading. International Journal of Vehicle Design, 13, 564-579. http://dx.doi.org/10.1504/IJVD.1992.061748

[16] Hamada, H. and Ramakrishna, S. (1995) Scaling Effects in the Energy Absorption of Carbon Fiber/PEEK Composite Tubes. Composites Science and Technology, 55, 211-221. http://dx.doi.org/10.1016/0266-3538(95)00081-X

[17] Mamalis, A.G., Manolakos, D.E., Ioannidis, M.B. and Papapostolou, D.P. (2006) The Static and Dynamic Axial Collapse of CFRP Square Tubes: Finite Element Modelling. Composite Structures, 74, 213-225. http://dx.doi.org/10.1016/j.compstruct.2005.04.006

[18] Fleming, D.C. (2011) Modelling Composite Crushing Initiation Using a Cohesive Element Formulation. International Journal of Crashworthiness, 16, 475-485. http://dx.doi.org/10.1080/13588265.2011.606999

[19] Feraboli, P., Wade, B., Deleo, F., Rassaian, M., Higgins, M. and Byar, A. (2011) LS-DYNA MAT54 Modeling of the Axial Crushing of a Composite Tape Sinusoidal Specimen. Composites Part A: Applied Science and Manufacturing, 42, 1809-1825. http://dx.doi.org/10.1016/j.compositesa.2011.08.004

[20] Boria, S. and Belingardi, G. (2012) Numerical Investigation of Energy Absorbers in Composite Materials for Automotive Applications. International Journal of Crashworthiness, 17, 345-356. http://dx.doi.org/10.1080/13588265.2011.648516

[21] Siromani, D., Awerbuch, J. and Tan, T.M. (2014) Finite Element Modeling of the Crushing Behavior of Thin-Walled CFRP Tubes under Axial Compression. Composites Part B: Engineering, 64, 50-58. http://dx.doi.org/10.1016/j.compositesb.2014.04.008

[22] Abdel-Haq, M., Broggiato, G.B. and Newaz. G.M. (1999) Constrain Effects on Energy Absorption in Unidirectional PMC Tubes. Journal of Composite Materials, 33, 774-793. http://dx.doi.org/10.1177/002199839903300901

[23] Quek, S.C., Waas, A.M., Homann, J. and Agaram, V. (2001) The Crushing Response of Braided and CSM Glass Reinforced Composite Tubes. Composite Structures, 52, 103-112. http://dx.doi.org/10.1016/S0263-8223(00)00195-1

[24] Beard, S.J. and Chang, F.K. (2002) Energy Absorption of Braided Composite Tubes. International Journal of Crashworthiness, 7, 191-206. http://dx.doi.org/10.1533/cras.2002.0214

[25] Warrior, N.A., Turner, T.A., Cooper, E. and Ribeaux, M. (2008) Effect of Boundary Conditions on the Energy Absorption of Thin-Walled Polymer Composite Tubes under Axial Crushing. Thin-Walled Structures, 46, 905-913. http://dx.doi.org/10.1016/j.tws.2008.01.023

[26] Yang, Y., Nakai, A. and Hamada, H. (2009) A Method to Improve the Energy Absorption Capability of Fiber-Reinforced Composite Tubes. International Journal of Crashworthiness, 14, 315-322. http://dx.doi.org/10.1080/13588260802674120

[27] Xiao, X., McGregor, C., Vaziri, R. and Poursartip, A. (2009) Progress in Braided Composite Tube Crush Simulation. International Journal of Impact Engineering, 36, 711-719. http://dx.doi.org/10.1016/j.ijimpeng.2008.09.006

[28] Siromani, D., Henderson, G., Mikita, D., Mirarchi, K., Park, R., Smolko, J., Awerbuch, J. and Tan, T.M. (2014) An Experimental Study on the Effect of Failure Trigger Mechanisms on the Energy Absorption Capability of CFRP Tubes under Axial Crushing. Composites Part A: Applied Science and Manufacturing, 64, 25-35. http://dx.doi.org/10.1016/j.compositesa.2014.04.019

[29] Jacob, G.C., Fellers, J.F., Starbuck, J.M. and Simunovic, S. (2004) Crashworthiness of Automotive Composite Material Systems. Journal of Applied Polymer Science, 92, 3218-3225. http://dx.doi.org/10.1002/app.20336

[30] Ueda, M., Anzai, S. and Kubo, T. (2014) Progressive Crushing of a Unidirectional CFRP Plate with V-Shaped Trigger. Advanced Composite Materials, 23. http://dx.doi.org/10.1080/09243046.2014.882540

[31] Thornton, P.H. and Jeryan, R.A. (1988) Crash Energy Management in Composite Automotive Structures. International Journal of Impact Engineering, 7, 167-180. http://dx.doi.org/10.1016/0734-743X(88)90024-3

[32] Farley, G.L. (1991) The Effects of Crushing Speed on the Energy-Absorption Capability of Composite Tubes. Journal of Composite Materials, 25, 1314-1329.

[33] Lavoie, J.A. and Kellas, S. (1996) Dynamic Crush Tests of Energy-Absorbing Laminated Composite Plate. Composites Part A: Applied Science and Manufacturing, 27, 467-475. http://dx.doi.org/10.1177/002199839102501004 
Scientific Research Publishing (SCIRP) is one of the largest Open Access journal publishers. It is currently publishing more than 200 open access, online, peer-reviewed journals covering a wide range of academic disciplines. SCIRP serves the worldwide academic communities and contributes to the progress and application of science with its publication.

Other selected journals from SCIRP are listed as below. Submit your manuscript to us via either submit@scirp.org or Online Submission Portal.
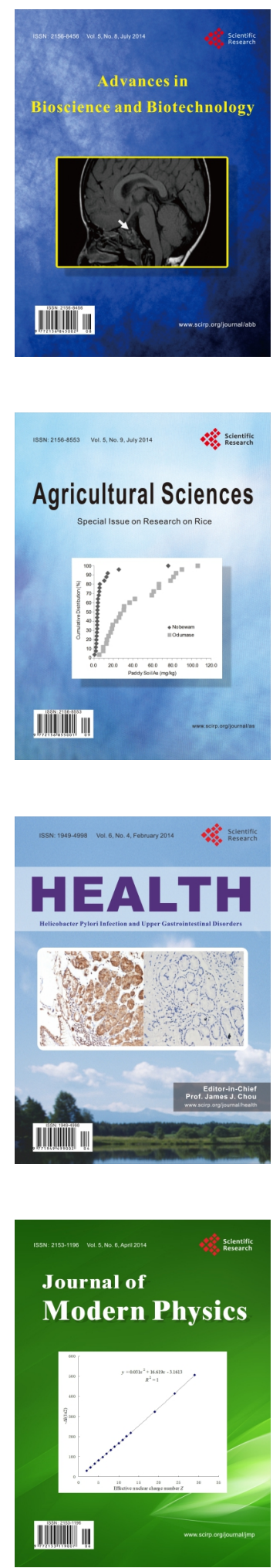
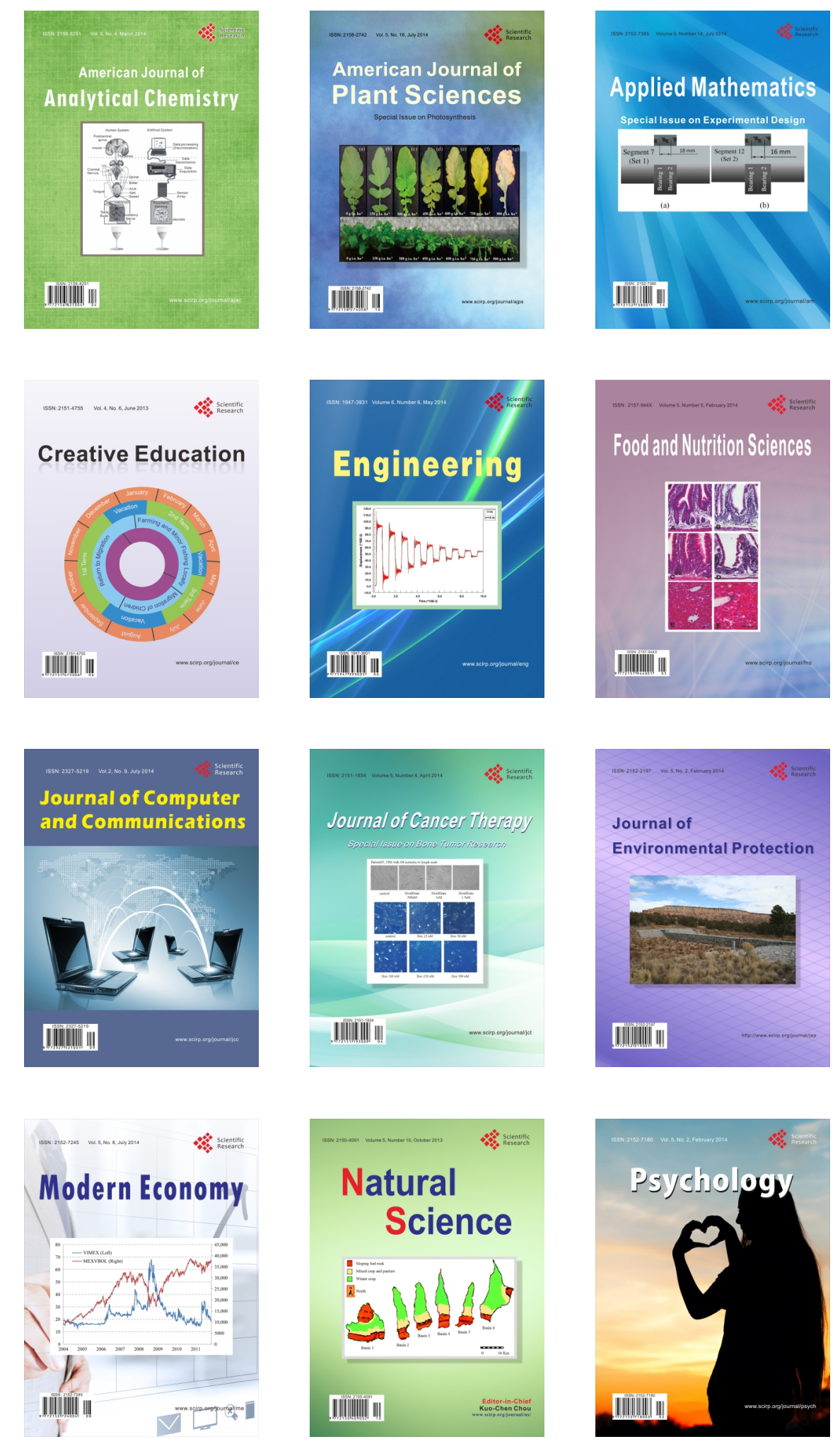